\title{
Angio-immunoblastic lymphadenopathy: a case with a 17-year follow-up
}

\author{
MiRIAM OCHSHORN \\ M.D. \\ MORDECHAI TCHETCHIK \\ M.D.
}

\author{
Rita Michalevicz $\dagger$ \\ M.D.
}

Albert Behar $\dagger$

M.D.

\section{URI SeLigSOHN* M.D.}

The Department of Internal Medicine $C$ and The Institutes of Hematology* and $†$ Pathology, Tel-Aviv Medical Center and The Sackler School of Medicine, Tel-Aviv University, Israel

\begin{abstract}
Summary
A case of angioimmunoblastic lymphadenopathy with a 17-year follow-up is reported. The patient, who first presented with benign hypergammaglobulinaemic purpura of Waldenstrom and autoimmune haemolytic anaemia appears to be the longest survivor with this condition reported so far.

The marked variations in the clinical course of patients with angio-immunoblastic lymphadenopathy in conjunction with immunological characteristics are discussed.
\end{abstract}

\section{Introduction}

In 1973, a clinicopathological entity called 'Immunoblastic lymphadenopathy' was described (Lukes and Tindle, 1973). A year later, 15 similar cases called angioimmunoblastic lymphadenopathy with dysproteinemia' (AILD) were published (Frizzera, Moran and Rappaport, 1974).

AILD is a disease which manifests itself in most patients by an aggressive course although about onethird of the patients survive more than two years (Cullen et al., 1979). AILD has been described in association with autoimmune disorders, drugs and other conditions. However, it has not been reported (Kyle et al., 1971) preceded by benign hyperglobulinaemic purpura of Waldenstrom (BHPW).

A patient is reported in whom the first presentation was with BHPW and Coombs' positive haemolytic anaemia. The diagnosis of AILD was established later by a lymph node biopsy.

Address for reprints: Dr M. Ochshorn, Department of Internal Medicine C, Rokah Hospital, Balfour Street, Tel-Aviv, Israel.

\section{Case report}

A 76-year-old woman of Yemenite Jewish origin was first admitted to our medical centre in 1964 at the age of 59 years because of a purpuric rash of her lower limbs and marked weakness. On examination she had hepatosplenomegaly (liver and spleen palpable $3 \mathrm{~cm}$ and $4 \mathrm{~cm}$ respectively below the costal margin), enlarged axillary lymph nodes and a purpuric rash on both feet and calves. Laboratory tests revealed a haemoglobin level of $6.1 \mathrm{~g} / \mathrm{dl}$, a platelet count of $140 \times 10^{9} / 1$, a reticulocyte count of $10 \%$, a white blood cell count of $2.8 \times 10^{9} / 1$ with $79 \%$ neutrophils, $2 \%$ eosinophils, $4 \%$ monocytes and $15 \%$ lymphocytes. Bilirubin level was $\mathbf{3 4 . 2} \mu \mathrm{mol} / \mathrm{l}$, haptoglobin was below the normal level, direct Coombs' test was positive, the half life of chromium ${ }^{51}$ labelled red cells was 5 days. Total protein was $72 \mathrm{~g} / \mathrm{l}$ with $34 \mathrm{~g} / \mathrm{l}$ albumin and $38 \mathrm{~g} / 1$ globulin. Serum electrophoresis disclosed hypergammaglobulinaemia. Serum immunoelectrophoresis showed a diffuse elevation in the gamma globulins. Routine chemistry studies, L.E. cells and Rose-Waaler were negative. Chest X-rays, a complete gastrointestinal series and cholecystography were normal.

Liver biopsy showed swollen hepatocytes with slight granulation and brown pigment. A few portal spaces were infiltrated by a small number of lymphocytes and plasma cells. Skin biopsy from an area with purpura showed granulocyte and lymphocyte infiltration of small vessels, compatible with vasculitis.

In view of the clinical manifestations and findings, the diagnosis of BHPW with autoimmune haemolytic anaemia was established. The patient received 3 


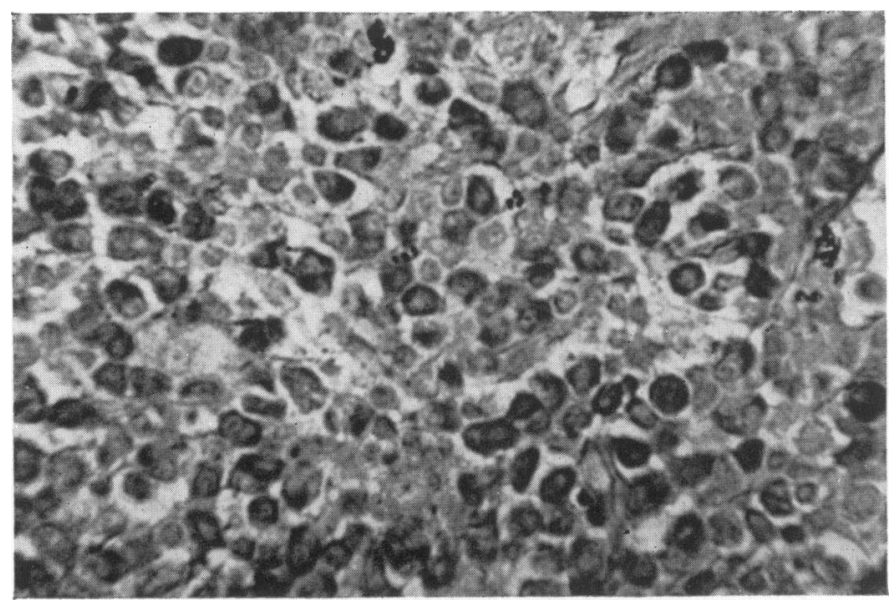

Fig. 1. A dense cellular infiltrate obliterating the normal lymph node architecture. The infiltrate consists of plasmocytic cells, small lymphocytes, cleaved and non-cleaved. There is also a small number of immunoblasts, which are the largest cells, with a large nucleus containing a prominent central nucleolus or several small nucleoli adjacent to the nuclear membrane.

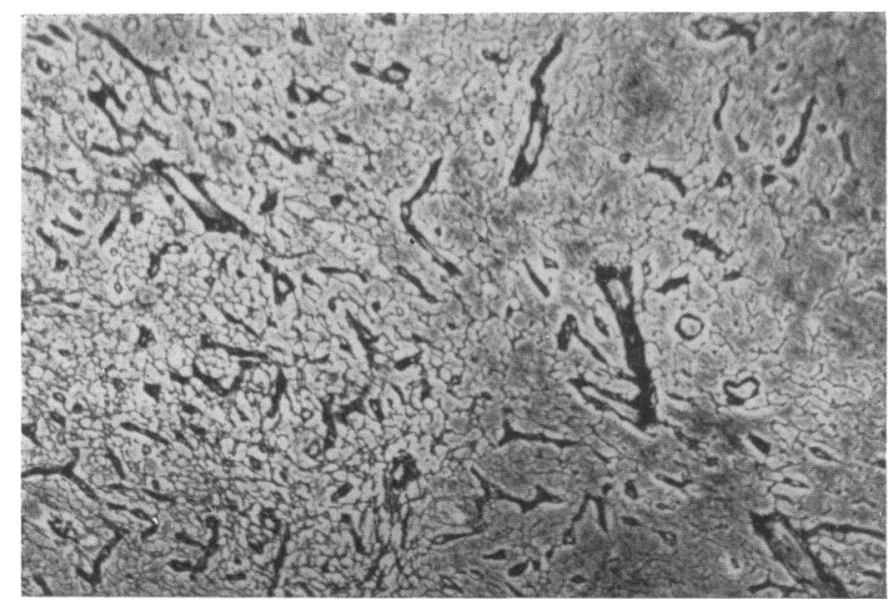

Fig. 2. Marked proliferation of arborizing postcapillary venules throughout the lymph node, most prominently in the $\frac{0}{3}$. subcortical areas.

packed cell units and therapy with $30 \mathrm{mg}$ prednisone per day was initiated. Her general condition improved, the haemoglobin level rose to $9.0 \mathrm{~g} / \mathrm{dl}$ and she left the hospital on $10 \mathrm{mg}$ prednisone as a maintenance dose.

From 1964 the patient was hospitalized twelve times because of fever, haemolytic crisis, purpura, skin rashes, cough and dyspnoea. On several occasions lung infiltrates were observed. The patient always responded to treatment with prednisone up to $60 \mathrm{mg}$ /day. Interestingly, during two hospitalizations because of purpura and fever the patient recovered without any treatment. Usually no treatment was given between hospitalizations.
The patient was readmitted in 1980 with the same manifestations, namely fever, chills, weakness and 은 dyspnoea. Physical examinations revealed the find- $-\frac{D}{O}$ ings she had had for years: hepatosplenomegaly, enlarged axillary and inguinal lymph nodes, and $N$ pigmented legs. Laboratory studies revealed haemo- $\mathrm{N}$ globin level of $4.5 \mathrm{~g} / \mathrm{dl}$, reticulocyte count of $15-20 \%$, N bilirubin level of $77 \mu \mathrm{mol} / 1$ of which $17 \cdot 1 \mu \mathrm{mol} / 1$ was $\omega$ direct, diffuse hypergammaglobulinaemia (IgG 27.1으 $\mathrm{g} / \mathrm{l}$, IgA $6.3 \mathrm{~g} / \mathrm{l}$ and $\operatorname{IgM} 2.92 \mathrm{~g} / \mathrm{l}$ ). Bone marrow aspirate showed erythroid hyperplasia with megalo- $\Phi_{\mathscr{Q}}$ blastic changes. The karyotype was normal. The $\stackrel{?}{?}$ Coombs' test was strongly positive $(1: 400)$. The $\frac{0}{0}$ antibody on the red cells was mainly $\operatorname{IgG}_{1}$, but also $\underset{\mathbb{D}}{\stackrel{D}{D}}$ 
some $\mathrm{IgG}_{2}, \mathrm{IgG}_{3}$, and $\mathrm{IgG}_{4}$ and a minimal amount of $\mathrm{C}_{4}$ were observed. $\mathrm{C}_{4}$ level in the serum was low: $0.09 \mathrm{~g} / 1$ (normal values $0.2-0.5 \mathrm{~g} / \mathrm{l}$ ), $C_{3} 0.75 \mathrm{~g} / \mathrm{l}$ (normal) and the total haemolytic activity $58 \%$ (normal 22-55\%).

An inguinal lymph node was biopsied, the histological picture of which was compatible with the diagnosis of AILD. There was diffuse replacement of the normal lymph node architecture by a pleomorphic cellular infiltrate consisting of various types of lymphoid cells: small lymphocytes, plasmocytes, histiocytes, many mast cells and most prominently, immunoblasts (Fig. 1). A truly striking feature, particularly with the reticulin stain, was the tremendous proliferation with arborization of postcapillary venules observed throughout the section (Fig. 2).

The patient was treated with $60 \mathrm{mg}$ prednisone per day, 4 packed cell units, cephalexin $2 \mathrm{~g} /$ day and folic acid $10 \mathrm{mg} /$ day. Her condition improved gradually, fever subsided, haemoglobin level rose to $10.4 \mathrm{~g} / \mathrm{dl}$. The Coombs' test became weakly positive $(1: 20)$, the red cells being coated only with $\operatorname{IgG}_{1}$.

Some immunological studies were performed when the patient was on corticosteroids. Surface immunoglobulin bearing cells (B cells) IgG 9\%, IgA $13 \%$, IgM $22 \%$, IgD $14 \%$ (upper limit of normal range being IgG $10 \%$, IgA $4 \%$, IgM $2 \%$ and IgD $8 \%$ ). $\mathrm{E}$ rosettes (T cells) $70 \%$ (normal range $75-85 \%$ ).

Following her discharge from the hospital the patient was followed for about 6 months while receiving $20 \mathrm{mg}$ prednisone per day. Her condition remained stable although her haemoglobin level did not exceed $10 \mathrm{~g} / \mathrm{dl}$. In October 1980 3-week courses of treatment with cyclophosphamide $200 \mathrm{mg}$ /day for 5 days and prednisone $50 \mathrm{mg} /$ day for 5 days were initiated. As of December 1980 her haemoglobin level reached $14.7 \mathrm{~g} / \mathrm{dl}$ and the splenomegaly and lymphadenopathy disappeared.

\section{Discussion}

An unusually prolonged benign clinical course in a patient with AILD has been outlined. For the last seventeen years the patient has been manifesting periodic episodes of fever, purpura, pruritus, haemolytic crises and persistent lymphadenopathy, hepatosplenomegaly and polyclonal hypergammaglobulinaemia. At her first presentation, in 1964, she was diagnosed as having benign hypergammaglobulinaemic purpura of Waldenstrom (BHPW). The criteria for establishing the diagnosis of BHPW consist of recurrent episodes of purpuric vasculitis, usually in the lower limbs, and polyclonal hypergammaglobulinaemia (Waldenstrom, 1943) and the finding in the majority of patients of circulating immune complexes (Kyle et al., 1971). In about half of the patients BHPW is primary whereas in the rest it precedes by several years the development of chronic lymphocytic leukaemia, Sjögren's syndrome, keratoconjuctivitis sicca, systemic lupus erythematosus and other collagen diseases (Kyle et al., 1971).

To the best of our knowledge, BHPW has not been reported as preceding AILD. Purpuric vasculitis and hypergammaglobulinaemia are manifestations of AILD as well as of BHPW. Therefore, on the basis of only these features, the distinction between the two disorders is difficult. When our patient first presented, several features such as Coombs' positive haemolytic anaemia, hepatosplenomegaly and lymphadenopathy were indeed very unusual for BHPW yet in those days AILD had not been defined as an entity. In retrospect the initial presentation was very typical of AILD.

AILD has an unpredictable course and is usually complicated by exacerbations and infections. Lukes and Tindle (1975) reviewed 32 cases and found the course of the disease to be usually progressive, with a median survival of 15 months in 18 fatal cases. In three of the cases, AILD evolved into immunoblastic sarcoma. Frizzera, Moran and Rappaport (1975) divided their 24 cases into two groups regardless of the treatment: those with a long survival (24-67 months) and those who succumbed to the disease in less than two years. The clinical course in our patient is in sharp contrast to these observations on the rather poor prognosis of patients with AILD. Interestingly, the observed exacerbations in our patient have been managed easily by short-term administration of corticosteroids and sometimes have subsided spontaneously.

During the last hospitalization, since the haemoglobin level did not exceed $10 \mathrm{~g} / \mathrm{dl}$, oral cyclophosphamide was added to steroids. After three courses of cyclophosphamide and prednisone, the clinical condition of the patient improved and the haemoglobin level raised to $14 \mathrm{~g} / \mathrm{dl}$. Corticosteroids are recommended as the first line therapy in AILD, although less than half the patients achieve complete remission (Cullen et al., 1979). The use of cytotoxic agents has been advocated by some with good results as the initial therapy (Cullen et al., 1979) but the enhancement of severe infections may contraindicate their use (Lukes and Tindle, 1975).

The uncertainty about the nature of AILD and the difficulties in predicting the course of the disease have made a rational approach to treatment impossible. Half of the cases of AILD have a positive direct Coombs' test with IgG and complement present on the red cells (Pruzanski, 1980). The antibody identified in our patient was mainly $\mathrm{IgG}_{1}$ and some $\mathrm{C}_{4}$ was also found. In cases of AILD it would be interesting to note whether this is a typical finding or not.

Some observers have stressed that AILD is a non- 
neoplastic hyperimmune state with B-cell hyperfunction due to an unknown stimulus (Lukes and Tindle, 1975) whilst others have stressed the presence of a $T$ cell defect (Frizzera et al., 1975). Thus, immunological studies (Kreisler et al., 1977) showed either a high or a normal percentage of B cells (Watanabe, 1977) and various percentages of $E$ rosettes (Rudders and DeLellis, 1977). In our patient a high percentage of lymphocytes with surface immunoglobulin was found and noticeable was the relatively high proportion of $\operatorname{IgD}$ and $\operatorname{IgM}$ bearing cells. A slightly decreased percentage of T-cells was also observed. Unfortunately, these immunological abnormalities were found while the patient was receiving corticosteroids. So far we have been unable to repeat these studies while the patient has been off treatment.

In view of the marked variations in the clinical course of patients with AILD it appears advisable to characterize the immunological abnormalities in conjunction with other features of the disease and hopefully discern patterns which may have a bearing on its prognosis.

\section{References}

Cullen, M.H., Stansfeld, A.G., Oliver, R.T.D., Lister, T.A. \& MalPaS, J.S. (1979) Angio-immunoblastic lymphadenopathy: Report of ten cases and review of the literature. Quarterly Journal of Medicine, 189, 151.
Frizzera, G., Moran, E.M. \& RapPaport, H. (1974) Angioimmunoblastic lymphadenopathy with disproteinemia. Lancet, i, 1070.

Frizzera, G., Moran, E.M. \& RapPaPort, H. (1975) Angio- $c$ immunoblastic lymphadenopathy-Diagnosis and clinical $\overrightarrow{\vec{F}}$ course. American Journal of Medicine, 59, 803.

Kreisler, J.M., Moreno, E., Moneo, I., Bootello, A., Bouza, E., Martinez De Letona, J. \& Sanaya, A. (1977) ㅎ Immunological findings in immunoblastic lymphadeno- $\overline{\bar{\omega}}$ pathy. A detailed case study. Clinical and Experimental $\stackrel{\mathbb{D}}{\mathbb{D}}$ Immunology, 27, 497.

Kyle, R.A., Gliech, G.J., Bayrd, E.D. \& Vaughan, J.H. پొ (1971) Benign hypergammaglobulinemic purpura of Waldenstrom. Medicine (Baltimore), 50, 113.

Lukes, R.J. \& TINDle, B.H. (1973) Immunoblastic lymphadenopathy: a new hyperimmune entity resembling $\vec{\omega}$ Hodgkin's diseases. Presented at the workshop on Classification of non-Hodgkin's Lymphomas. University of Chicago, June 25-29.

LuKES, R.J. \& TINDLE, B.H. (1975) Immunoblastic lymphadenopathy-A hyperimmune entity resembling Hodgkin's disease. New England Journal of Medicine, 292, 1.

Pruzanski, W. (1980) Lymphadenopathy associated with dysgammaglobulinemia. Seminars in Hematology, 17, 44.

RUdDers, R.A. \& DeLellis, R. (1977) Immunoblastic lymphadenopathy. A mixed proliferation of $T$ and $B O$ lymphocytes. American Journal of Clinical Pathology, 68, 518.

WALDENSTROM, J. (1943) Kliniska metoder for pavisande av hyperproteinami och deras pratiska varde for disgnostiken. $\bar{\Phi}$ Nordisk Medicin, 20, 2288.

Watanabe, H. (1977) Association of immunoblastic lymp\&- $\vec{\emptyset}$ adenopathy and Hashimoto's thyroiditis. Annals of Interng Medicine, 87, 62. 